\title{
The prognostic value of muscle regional oxygen saturation index in severe community-acquired pneumonia: a prospective observational study
}

\author{
Laura Claverias ${ }^{1,2^{*}}$ D , Michael Mari ${ }^{1}$, Judith Marín-Corral ${ }^{1}$, Mónica Magret ${ }^{1}$, Sandra Trefler ${ }^{1,2}$, María Bodi $^{1,2}$,
} Antonio García-España², Juan Carlos Yébenes ${ }^{5}$, Sergi Pascual ${ }^{3,4}$, Joaquim Gea ${ }^{3,4}$ and Alejandro Rodríguez ${ }^{1,2}$

\begin{abstract}
Background: Community-acquired pneumonia (CAP) mortality exceeds $20 \%$ in critical care patients despite appropriate antibiotic therapy. Regional tissue oxygen saturation index ( $\mathrm{rSO} 2)$ measured with near-infrared spectroscopy (NIRS) might facilitate early detection for patients at risk of serious complications. Our objectives were to determine the relationship between early determination of $\mathrm{rSO}_{2}$ and mortality and to compare discrimination power for mortality of $\mathrm{rSO}_{2}$ and other resuscitation variables in critically ill CAP patients.

Methods: This is a prospective observational study. Patients with CAP were enrolled within $6 \mathrm{~h}$ to intensive care admission. Demographics and clinical variables were recorded. rSO2 was determined using NIRS in brachioradialis muscle. All variables were determined at baseline and $24 \mathrm{~h}$ after admission.

Results: Forty patients were enrolled. Fourteen patients (35\%) had a baseline rSO2 $<60 \%$ and 7 of them died (50\%). Only 1 of 26 (3.8\%) patients with $\mathrm{rSO} 2 \geq 60 \%$ died $(p=0.007)$. The area under ROC curve (AUROC) showed consistent mortality discrimination at baseline $(0.84, p=0.03)$ and at $24 \mathrm{~h}(0.86, p=0.006)$ for $\mathrm{rSO} 2$ values. Cox regression analysis showed that "low" rSO2 at ICU admission (hazard ratio (HR) = 8.99; $95 \%$ confidence interval (Cl) 1.05-76.8; $p=0.045$ ) and "low" rSO2 at $24 \mathrm{~h}(\mathrm{HR}=13.18 ; 95 \% \mathrm{Cl} 1.52-113.6 ; p=0.019)$ were variables independently associated with mortality. In contrast, other variables such as Acute Physiology and Chronic Health Evaluation (APACHE II) score $(H R=1.09 ; 95 \% \mathrm{Cl} 0.99-1.19 ; p=0.052)$ were not associated with mortality.
\end{abstract}

Conclusions: Our findings suggest that forearm skeletal muscle rSO2 differs in patients with severe CAP according to outcome and might be an early prognosis tool.

Keywords: Community-acquired pneumonia, Sepsis, Septic shock, Microcirculation, Near-infrared spectroscopy

\section{Background}

Community-acquired pneumonia (CAP) is an important cause of morbidity, mortality and increased health-care costs [1-3]. CAP is considered severe when admission to the intensive care unit (ICU) is needed due to respiratory distress or septic shock and occurs in about 9-16\% of hospitalized patients $[4,5]$. In patients with severe

\footnotetext{
* Correspondence: Lauraclaverias@gmail.com

1Joan XXIII University Hospital, Critical Care Department, IISPV/URV, Carrer Dr. Mallafre Guasch 4, 43007, Tarragona, Spain

${ }^{2}$ Research Unit, Joan XXIII University Hospital, IISPV/URV, Tarragona, Spain Full list of author information is available at the end of the article
}

CAP, mortality rates ranged from 20 to $50 \%$ according to the presence of shock, the accuracy of process of care, need for mechanical ventilation and underlying diseases [1-9]. Prompt initiation of appropriate antibiotic therapy and adequate resuscitation are recommended as it potentially benefits patients' prognosis $[10,11]$ However, the mortality rate in immunocompetent patients admitted to the ICU by CAP with appropriate antibiotic therapy exceeds $20 \%$ [3] suggesting that antibiotics alone are not enough.

Microvascular alterations are recognized as a key characteristic contributing to organ dysfunction and death in 
patients with sepsis [12-14]. Microvascular dysfunction leads to reduced oxygen delivery and extraction, causing heterogeneous and deficient tissue oxygenation, which is associated with adverse clinical outcome.

Global hemodynamic and metabolic parameters are used in current practice as resuscitation endpoints in severe sepsis and septic shock [11]. However, normalization of relevant variables such as mean arterial pressure (MAP), central venous pressure (CVP), cardiac output (CO) or serum lactate is not enough to define oxygenation status and aerobic metabolism in peripheral tissues [15-21] Increasing evidence suggests that regional oxygen saturation index $\left(\mathrm{rSO}_{2}\right)$ determined by nearinfrared spectroscopy (NIRS) might allow early detection of patients at risk of serious complications and have prognostic implications $[17,18]$.

We hypothesized that brachioradialis muscle $\mathrm{rSO}_{2}$ could reflect the prognosis in patients with severe CAP.

\section{Methods}

\section{Ethics, consent and permissions}

The study was performed from January 2011 to December 2013 in a 30-bed medical-surgical ICU in a tertiary university hospital. It was a prospective single centre, observational clinical study. The investigation was conducted according to the principles outlined in the Declaration of Helsinki. The study protocol was approved by the Joan XXIII University Hospital Ethics Committee (MICRO2 20/2010), and informed consent was given by each patient or their next of kin.

\section{Study population}

Consecutive adult patients with severe CAP requiring admission to the ICU were enrolled. The diagnosis of CAP was based on (a) the detection of a new and persistent pulmonary infiltrate for which there is no other explanation and at least two of the following clinical criteria: (1) fever or hypothermia (temperature $>38$ or $<35.5{ }^{\circ} \mathrm{C}$ ); (2) leucopenia or leukocytosis (white blood cells $\leq 4 \times 10^{9} / \mathrm{L}^{-1}$ or $\geq 12 \times 10^{9} / \mathrm{L}^{-1}$ ) or (3) purulent respiratory secretions and (b) acquisition of the infection outside a hospital, long-term care facility or nursing home [22]. Patients were admitted to the ICU if they presented at least one of following criteria: signs and symptoms of respiratory failure (respiratory rate $>30 / \mathrm{min}$, accessory musculature utilization, low $\mathrm{SpO}_{2}$ despite oxygen supplementation), needed mechanical ventilation, or presented with criteria of severe sepsis or septic shock. All patients admitted to the ICU were considered to present severe CAP. We decided to include only CAP patients in order to obtain a homogeneous population of patients to increase the internal validity of the study.

We excluded (a) patients $<18$ years old; (b) immunosuppression, defined as any primary immunodeficiency or immunodeficiency secondary to HIV infection, active malignancies, radiation treatment or use of cytotoxic drugs, or steroids drugs (daily doses $>40 \mathrm{mg}$ of prednisolone or equivalent for $>2$ weeks), immunological disease, solid organ transplant and haematological disease; (c) hospitalacquired pneumonia or health-care-associated pneumonia; (d) morbid obesity (body mass index $>30 \mathrm{~kg} / \mathrm{m}^{2}$ ); (e) clinical edema and (f) injuries in forearms.

\section{Study protocol}

Patients were enrolled at ICU admission. Information collected included demographic characteristics, Acute Physiology and Chronic Health Evaluation (APACHE II) score [23], Sequential Organ Failure Assessment (SOFA) score [24] and global hemodynamic variables as heart rate (HR), CVP, MAP and mixed venous oxygen saturation $\left(\mathrm{SvO}_{2}\right)$ when possible. Serum lactate and base deficit were obtained as markers of resuscitation and were determined at baseline and $24 \mathrm{~h}$ after ICU admission. The patients were treated with fluid administration and vasopressor therapy as required, according to the local guidelines adapted from Surviving Sepsis Campaign guidelines [11]. Patients were monitored at ICU admission using a central venous pressure (CVP) or echocardiography depending on the attending physician's decision. Resuscitation was guided using CVP or echocardiography-derived parameters, and if advanced hemodynamic monitoring was needed, a pulmonary artery catheter was inserted. Fluid resuscitation was administered by fluid bolus challenge with crystalloids and/or artificial colloids, targeting a CVP $8-12 \mathrm{mmHg}$ or if the patient showed $>20 \%$ collapsibility of the inferior cava vein during inspiration in ventilated patients ( $>50 \%$ collapsibility in patients in spontaneous ventilation). When fluid administration was not enough to improve the patient's hemodynamic status, the vasopressor agent of choice was norepinephrine titrated to the $2 \mu \mathrm{g} / \mathrm{kg} /$ min maximum dose to maintain the MAP $>65 \mathrm{mmHg}$. Shock was defined as the need for vasopressors for $>4 \mathrm{~h}$ after fluid replacement [8]. In accordance with our local guidelines, all patients were treated with antibiotic combination therapy (ceftriaxone plus macrolide) for CAP. All patients were evaluated during the first $24 \mathrm{~h}$ after ICU admission. We recorded if, at the time of admission, patients met major criteria according to the American Thoracic Society (need of mechanical ventilation or shock) [25]. Treatment was administered by an independent physician team that was blinded for $\mathrm{rSO}_{2}$ values. Patients were followed up for outcome data until ICU discharge or ICU death.

\section{Regional oxygen saturation index $\left(\mathrm{rSO}_{2}\right)$ measurements}

A probe somasensor was placed on the medial forearm (brachioradialis muscle) at a distance $5 \mathrm{~cm}$ distal to the elbow of each subject to obtain skeletal muscle $\mathrm{rSO}_{2}$ 
measurement as described elsewhere [17, 18]. Measurements were obtained using a commercially available NIRS spectrometry system INVOS 5100C oximeter (Somanetics Corporation, Troy. MI, USA), with a nonsterile and disposable skin surface probe. This system functions with two NIRS probes, one with $30-\mathrm{mm}$ and the other with $40-\mathrm{mm}$ spacing between NIR light send and receive optical fibre tips. The $30-\mathrm{mm}$ signal is subtracted from the $40-\mathrm{mm}$ signal, with the intention of subtracting the skin and subcutaneous fat layer artefact from the underlying skeletal muscle. For all patients, $\mathrm{rSO}_{2}$ was recorded at baseline and at $24 \mathrm{~h}$. NIRS data was not used in patients' management. According to our previous data $[17,18]$, we defined a threshold in $<60 \%$ as a "low $\mathrm{rSO}_{2}$ ".

\section{Primary and secondary outcomes}

The main objective of this study was to determine the relationship between early brachioradialis $\mathrm{rSO}_{2}$ values and mortality. Secondary outcomes were to compare the discrimination power for ICU mortality of brachioradialis $\mathrm{rSO}_{2}$ with standard variables of resuscitation and to evaluate the patients' evolution according to the variation of $\mathrm{rSO}_{2}$ in the first $24 \mathrm{~h}$.

\section{Statistical analysis}

Discrete variables are expressed as counts (percentage) and continuous variables as means and standard deviations or medians within the 25th to 75th interquartile range (IQR). For demographic and clinical characteristics of the patients, differences between groups were assessed using the chi-square test and Fisher's exact test for categorical variables and the Student $t$ test, MannWhitney $U$ test or Kruskal-Wallis test for continuous variables. Pearson's correlation coefficient was used to assess the association between continuous variables. The concordance of the values obtained for different correlations was assessed using the intraclass correlation coefficient (ICC), based on the model of analysis of variance for repeated measures by the process reliability. Cumulative survival was assessed using Kaplan-Meier plot. Cox regression analysis was performed to determine which variables were independently associated with mortality. We included the variables that showed a significant association with mortality in the univariate analysis as covariables in the model: APACHE II score, $\mathrm{rSO}_{2}$ value, presence of shock and need for mechanical ventilation. The predictive values for skeletal $\mathrm{rSO}_{2}$ and the other variables of resuscitation were calculated using a receiver operator characteristic (ROC) curve, and the area under ROC curve (AUROC) was computed. The ROC graph was a plot of all the sensibility/specificity pairs resulting from continuously varying the decision threshold over the entire range of results observed. Data analysis was made using SPSS for Windows 13.0 (SPSS, Chicago, IL, USA). For all analyses, $p<0.05$ was considered significant.

\section{Results}

Forty patients with severe CAP were enrolled. Median APACHE II score and SOFA score were 17.0 (IQR = 12-21) and $4.0(\mathrm{IQR}=3-5)$ points respectively, with an overall ICU mortality of $20 \%$. Additional demographics, baseline and $24 \mathrm{~h}$ hemodynamic and biochemical data with simultaneous measurements of skeletal muscle $\mathrm{rSO}_{2}$ are shown in Table 1.

Non-survivors had higher APACHE II score, greater need for invasive mechanical ventilation and higher frequency of septic shock compared to survivors. All non-survivors had major ATS criteria.

We found no significant differences in hemodynamic and biochemical data according to evolution. Brachioradialis $\mathrm{rSO}_{2}$ was the only variable associated with mortality at admission and at $24 \mathrm{~h}$. Twenty-two patients $(55 \%)$ had shock at admission. Shock patients had lower $\mathrm{rSO}_{2}$ at baseline (59 \% [SD 10.7] vs. $67 \%$ [SD 8.9], $p<0.001)$ and at $24 \mathrm{~h}(61 \%$ [SD 11.5] vs. $72 \%$ [SD 10.6], $p<0.009)$ than patients without shock. However, we observed no significant correlation neither between MAP and $\mathrm{rSO}_{2}$ at baseline $(r=0.19, p=0.90)$ and at $24 \mathrm{~h}(r=0.07, p=0.68)$ nor with $\mathrm{rSO}_{2}$ and norepinephrine doses at baseline $(r=0.11$, $p=0.67)$ and at $24 \mathrm{~h}(r=-0.46, p=0.06)$. In contrast, serum lactate at $24 \mathrm{~h}$ showed a weak but significant correlation with $\mathrm{rSO}_{2}$ at $24 \mathrm{~h}(r=0.66, p=0.001)$. In all cases, the concordance was poor and it was not significant. A central venous catheter for CVP measurement was inserted in 22 patients, the rest of them were monitored using echocardiography-derived parameters. $\mathrm{SvO}_{2}$ was available in only $11(27,5 \%)$ patients. $\mathrm{SvO}_{2}$ values were 76 and $70 \%$ at baseline and at $24 \mathrm{~h}$, respectively. We observed no significant correlation between $\mathrm{rSO}_{2}$ and $\mathrm{SvO}_{2}$ at any time of the study (data not shown).

Patients with baseline "low $\mathrm{rSO}_{2}$ " had a significantly higher ICU mortality rate than patients with $\mathrm{rSO}_{2} \geq 60 \%$ (Fig. 1). Fourteen patients (35\%) had a baseline skeletal muscle $\mathrm{rSO}_{2}<60 \%$, and seven of them (50\%) died. In contrast, only one patient (3.8\%) with $\mathrm{rSO}_{2} \geq 60 \%$ died $(p=0.001)$. This represents more than sixfold increase in the risk of death (OR 6, 25; 95 \% CI 1.0-39.4) despite similar levels of severity of illness and resuscitation variables (Table 2). We differentiate patients according to variation of the value of $\mathrm{rSO}_{2}$ from ICU admission to $24 \mathrm{~h}$ later. Three types of trends were observed: (1) a group of patients which showed no improvement or a decrease in $\mathrm{rSO}_{2}$ value (no responders); (2) other group which showed an improvement in $\mathrm{rSO}_{2}$ value to reach $\mathrm{rSO}_{2}$ of $>60 \%$ at $24 \mathrm{~h}$ (responders); and (3) a group of patients in which the $\mathrm{rSO}_{2}$ value improved but did not reach $>60 \%$ at $24 \mathrm{~h}$ (partially responders). We observed different outcomes 
Table 1 Clinical characteristics, hemodynamic variables and biochemical data with simultaneous measurements of skeletal muscle $\mathrm{rSO}_{2}$ of 40 patients included

\begin{tabular}{|c|c|c|c|}
\hline Variable & Overall $(n=40)$ & Survivors $(n=32)$ & Non-survivors $(n=8)$ \\
\hline \multicolumn{4}{|l|}{ Demographic data } \\
\hline Age (years), mean (SD) & $55.5(15.9)$ & $53(16.4)$ & $65(9.8)^{*}$ \\
\hline Male, $n(\%)$ & $27(67.5)$ & $21(65.6)$ & $6(75.0)$ \\
\hline \multicolumn{4}{|l|}{ Severity of illness } \\
\hline APACHE II score at day 1, median (IQR 25-75) & $17(12-21)$ & $16(12-20)$ & $22(18-34)^{* *}$ \\
\hline SOFA score at day 1, median (IQR 25-75) & $4(3-5)$ & $4(3-5)$ & $4(3-8)$ \\
\hline Major ATS criteria, median (IQR 25-75) & $28(70)$ & $20(62.5)$ & $8(100)^{* *}$ \\
\hline Invasive mechanical ventilation, $n(\%)$ & $21(52.5)$ & $13(40.6)$ & $8(100)^{* * *}$ \\
\hline Severe sepsis, $n(\%)$ & $18(44.5)$ & $17(53.1)$ & $1(12.5)$ \\
\hline Septic shock, $n(\%)$ & $22(55.5)$ & $15(46.9)$ & $7(87.5)^{*}$ \\
\hline \multicolumn{4}{|l|}{ Mean comorbidities, $n$ (\%) } \\
\hline Tobacco use & $3(8.6)$ & $3(10.7)$ & 0 \\
\hline Chronic obstructive pulmonary disease & $12(33.3)$ & $10(34.3)$ & $2(28.6)$ \\
\hline Cardiac disease & $8(20)$ & $6(18.7)$ & $2(28.6)$ \\
\hline Diabetes mellitus & $7(20)$ & $5(17.9)$ & $2(28.6)$ \\
\hline Severe liver disease & $1(2.9)$ & 0 & $1(14.3)$ \\
\hline \multicolumn{4}{|l|}{ Hemodynamic data, median (IQR 25-75) } \\
\hline Heart rate, b/min & $105(86-114)$ & $105(87-114)$ & $105(85-113)$ \\
\hline Heart rate at $24 \mathrm{~h}$ & $90(77-100)$ & $92(79-103)$ & 85 (70-99) \\
\hline Mean arterial pressure, $\mathrm{mmHg}$ & $79(71-94)$ & $78(72-98)$ & $80(69-88)$ \\
\hline Mean arterial pressure at $24 \mathrm{~h}$ & 79 (70-93) & $76(70-96)$ & $79(71-90)$ \\
\hline Central venous pressure, $\mathrm{mmHg}$ & $11(9-15)$ & $11(8-15)$ & $11(10-14)$ \\
\hline Central venous pressure at $24 \mathrm{~h}$ & $13(13-16)$ & $11(7-16)$ & $14(12-15)$ \\
\hline Mixed venous oxygen saturation, $\%^{\mathrm{a}}$ & $76(70-79)$ & $76(69-79)$ & $74(74)$ \\
\hline Mixed venous oxygen saturation at $24 \mathrm{~h}^{\mathrm{a}}$ & $70(68-83)$ & $70(68-80)$ & $80(70-91)$ \\
\hline \multicolumn{4}{|l|}{ Biochemical data, mean (SD) } \\
\hline Baseline serum lactate, mM/L & $3.0(3.1)$ & $2.5(1.6)$ & $4.8(6.1)$ \\
\hline Serum lactate at $24 \mathrm{~h}$ & $2.0(2.2)$ & $1.4(0.6)$ & $3.9(4.0)$ \\
\hline Baseline base deficit & $-3.5(5.2)$ & $-3.6(5.4)$ & $-2.7(4.3)$ \\
\hline Base deficit at $24 \mathrm{~h}$ & $-2.3(4.1)$ & $-1.9(4.1)$ & $-3.4(4.2)$ \\
\hline Baseline haemoglobin levels, mg \% & $11.9(1.8)$ & $12.1(1.9)$ & $11.2(1.1)$ \\
\hline Haemoglobin levels at $24 \mathrm{~h}$ & $10.6(1.7)$ & $10.6(1.9)$ & $10.4(1.1)$ \\
\hline Baseline serum glucose, mg \% & $166(74.7)$ & $158(75.3)$ & $197(66.8)$ \\
\hline Serum glucose at $24 \mathrm{~h}$ & $152(75.6)$ & $144(79.4)$ & $177(58.7)$ \\
\hline Baseline arterial pH & $7.34(0.1)$ & $7.40(0.1)$ & $7.34(0.3)$ \\
\hline Arterial pH at $24 \mathrm{~h}$ & $7.36(0.07)$ & $7.30(0.07)$ & $7.32(0.1)$ \\
\hline Baseline serum creatinine, mg \% & $1.40(0.9)$ & $1.38(1.03)$ & $1.41(0.8)$ \\
\hline Serum creatinine at $24 \mathrm{~h}$ & $1.1(0.59)$ & $0.9(0.4)$ & $1.5(0.9)$ \\
\hline \multicolumn{4}{|l|}{$\mathrm{rSO}_{2}$ brachioradialsis } \\
\hline Baseline $\mathrm{rSO}_{2}$, mean (SD) & $62.9(10.7)$ & $68(61-72)$ & $46(43-57)^{* * *}$ \\
\hline $\mathrm{rSO}_{2}$ at $24 \mathrm{~h}$, mean (SD) & $65.4(12.3)$ & $69(60-76)$ & $52(41-57)^{* * *}$ \\
\hline Baseline $\mathrm{rSO}_{2}<60, n(\%)$ & $14(35)$ & $7(21.9)$ & $7(87.5)^{* * *}$ \\
\hline $\mathrm{rSO}_{2}<60$ at $24 \mathrm{~h}, n(\%)$ & $6(15.8)$ & $4(12.5)$ & $7(87.5)^{* * *}$ \\
\hline
\end{tabular}


Table 1 Clinical characteristics, hemodynamic variables and biochemical data with simultaneous measurements of skeletal muscle $\mathrm{rSO}_{2}$ of 40 patients included (Continued)

\begin{tabular}{|c|c|c|c|}
\hline \multicolumn{4}{|l|}{ Therapy, mean (SD) } \\
\hline Norepinephrine at baseline $\mu \mathrm{g} / \mathrm{kg} / \mathrm{min}$ & $0.35(0.26)$ & $0.40(0.14)$ & $0.29(0.36)$ \\
\hline Norepinephrine at 24 h, $\mu \mathrm{g} / \mathrm{kg} / \mathrm{min}$ & $0.35(0.29)$ & $0.22(0.28)$ & $0.52(0.23)^{*}$ \\
\hline Fluid balance at $24 \mathrm{~h}, \mathrm{~mL}$ & $1650(1350)$ & $1470(800)$ & $2300(2500)$ \\
\hline \multicolumn{4}{|l|}{ ICU length of stay } \\
\hline Median IQR 25-75 \% & $18(11-30)$ & $18(11-31)$ & $24(8-30)$ \\
\hline
\end{tabular}

SD standard deviation, IQR interquartile range, APACHE /I Acute Physiology and Chronic Health Evaluation, SOFA Sequential Organ Failure Assessment, ATS American Thoracic Society, $r \mathrm{SO}_{2}$ regional oxygen saturation index

For survivors vs. non-survivors comparison ${ }^{*} p=0.01 ;{ }^{* *} p<0.05 ;{ }^{* * *} p<0.001$

${ }^{a}$ Only 11 patients

according to initial $\mathrm{rSO}_{2}$ variation with a higher mortality rate in "no responders" $(n=3 / 7,42.9 \%)$ and "partially responders" ( $n=3 / 7,42.9 \%)$ patients than "responder patients" $(n=1 / 26,3.8 \%, p<0.005)$ with an $\mathrm{OR}=18.7,95 \%$ CI 1.17-625.6 and a log rank $=5.99, p=0.05$ (Fig. 2). In addition, we performed a Cox regression analysis to determine if $\mathrm{rSO}_{2}<60 \%$ was associated with mortality. The regression analysis showed that "low" $\mathrm{rSO}_{2}$ at ICU admission (hazard ratio $(\mathrm{HR})=8.99 ; 95 \%$ CI $1.05-76.8 ; p=$ $0.045)$ and "low" $\mathrm{rSO}_{2}$ at $24 \mathrm{~h}(\mathrm{HR}=13.18$; $95 \% \mathrm{CI} 1.52$ 113.6; $p=0.019$ ) were variables independently associated with mortality. In contrast, APACHE II score (HR = 1.09; $95 \%$ CI $0.99-1.19 ; p=0,052)$ was not associated with mortality (Table 3$)$.

Finally, the discriminatory ability of each variable for ICU mortality was measured using the area under ROC curves (AUC). The AUC showed consistent mortality discrimination at baseline $(0.84 ; 95 \%$ CI $0.626-1.057$, $p=0.004)$ and at $24 \mathrm{~h}(0.86 ; 95 \%$ CI $0.646-1.075, p=0.002)$ for $\mathrm{rSO}_{2}$ values, better than other resuscitation variables (Table 4).

\section{Discussion}

The main finding of our study is that in a population of patients with severe CAP, an early value of skeletal muscle $\mathrm{rSO}_{2}<60 \%$ was associated with a worse prognosis despite similar severity of illness, representing near sixfold increase in the risk of death compared with patients with $\mathrm{rSO}_{2} \geq 60 \%$. In addition, $\mathrm{rSO}_{2}$ variation (from admission to $24 \mathrm{~h}$ ) allowed distinguishing three different types of responses to treatment which were associated with different evolution. To the best of our knowledge, our data is the first to report the relationship between $\mathrm{rSO}_{2}$ alterations and CAP prognosis with this NIRS device.

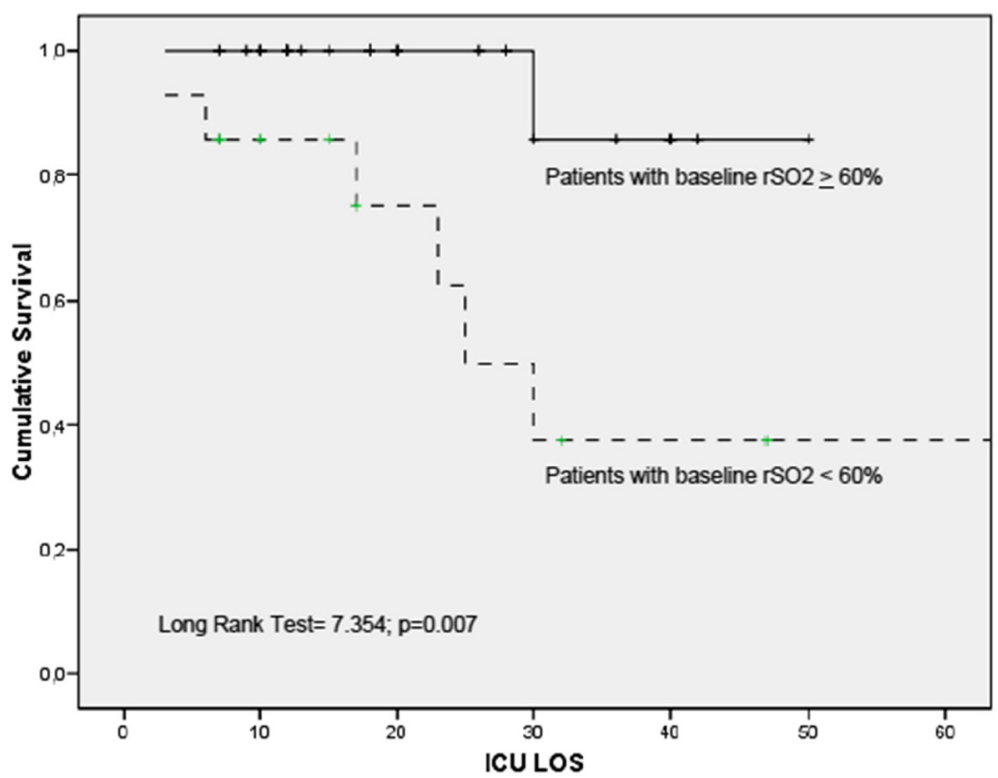

Fig. 1 Survival graph (Kaplan-Meier plot) for patients according baseline $\mathrm{rSO}_{2}$ cut-off values. ICU LOS intensive care unit length of stay (days), rSO regional oxygen saturation index 
Table 2 Levels of severity of illness and baseline resuscitation variables in 40 patients with severe community-acquired pneumonia according to basal brachioradialis muscle $\mathrm{rSO}_{2}$

\begin{tabular}{llll}
\hline Variable & $\mathrm{rSO}_{2}<60 \%(n=14)$ & $\mathrm{rSO}_{2} \geq 60 \%(n=26)$ & $p$ value \\
\hline APACHE II score, median (IQR 25-75) & $18(15-22)$ & $15(12-22)$ & 0,26 \\
SOFA score, median (IQR 25-75) & $4,5(3-5,5)$ & $4(3-5)$ & $75(71,7-94,7)$ \\
MAP (mmHg), median (IQR 25-75) & $84(69,7-93)$ & $2,3(1,5)$ & 0,73 \\
$\mathrm{SL}(\mathrm{mM} / \mathrm{L})$, mean (SD) & $4,2(4,8)$ & $-4,4(3,9)$ & 0,17 \\
BD, mean (SD) & $-1,7(6,7)$ & $0,32(0,32)$ & 0,11 \\
Catecholamines ( $\mu \mathrm{g} / \mathrm{kg} / \mathrm{min})$, mean (SD) & $0,39(1,5)$ & $1450(759)$ & 0,66 \\
Fluid balance at 24 h (mL), mean (SD) & $2130(2200)$ & $13(50)$ & 0.18 \\
Need for MV, $n(\%)$ & $8(57)$ & $1(3,8)$ & 0,58 \\
ICU mortality rate, $n(\%)$ & $7(50)$ & 0,001 \\
\hline
\end{tabular}

APACHE I/ Acute Physiology and Chronic Health Evaluation, SOFA Sequential Organ Failure Assessment, MAP medium arterial pressure, SL serum lactate, BD base deficit, $r \mathrm{SO}_{2}$ regional oxygen saturation index, $M V$ mechanical ventilation, IQR interquartile range, $S D$ standard deviation

Despite advances in diagnosis and antimicrobial therapy, severe CAP remains an important cause of morbidity and mortality, especially in patients requiring ICU admission [1-6]. Unfortunately, it remains unknown whether specific clinical conditions or biomarkers can be used to identify patients with potential high risk of death.

Several risk factors that predict which patients will develop moderate to severe CAP have been identified in a small number of studies [1-3]. Our group [26] found that a prompt oxygenation assessment in the emergency department shortened the time taken to initiate antibiotic therapy and improved survival. Practice guidelines based on severity assessment tools, such as the ATS admission criteria or CURB-65 score, allow high-risk patients to be identified and given specific treatment. However, the prediction rule is derived from clinical data and laboratory parameters which are time-consuming, thereby limiting the clinical applications of predictive outcomes [27, 28]. Several biomarkers have been proposed to assess severity of illness and outcome. Inflammatory cytokines such as interleukin-6, procalcitonin, albumin and C-reactive protein levels have also shown to predict the severity of illness and 28-day mortality $[29,30]$. However, most of these factors merely reflect individual coagulation and inflammation status and have no therapeutic potential in themselves. Therefore,

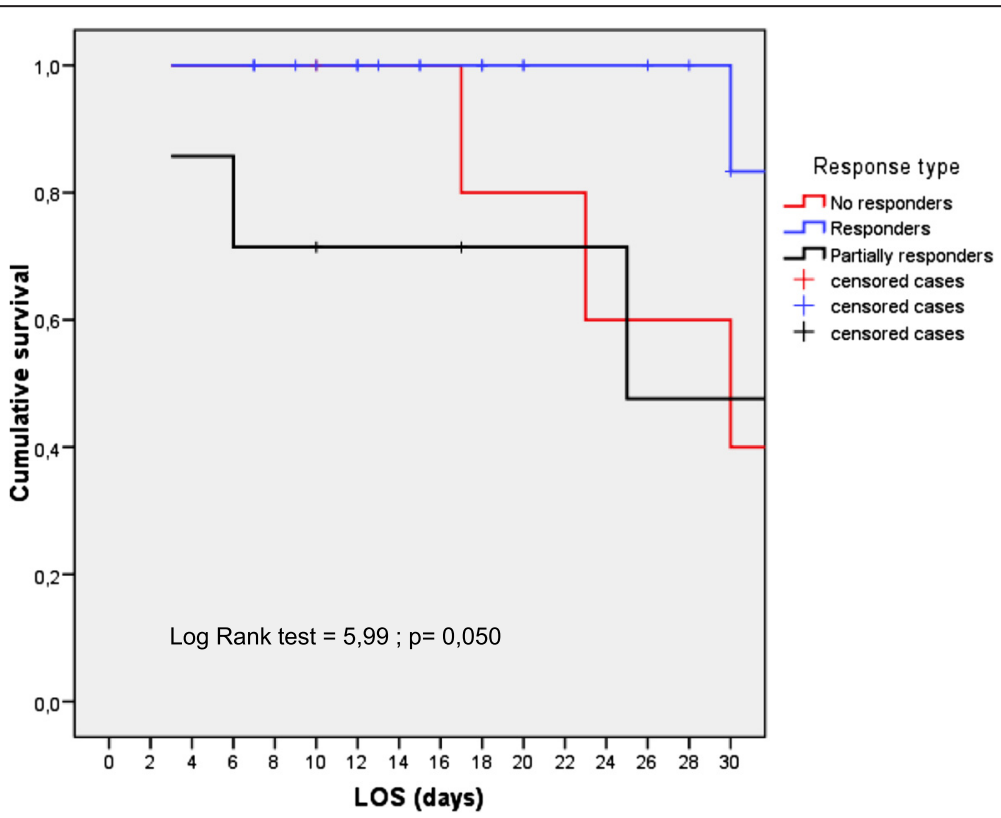

Fig. 2 Survival graph (Kaplan-Meier plot) for patients according to variation (0-24 h) of $\mathrm{rSO}_{2}$ with treatment. No responders: which showed no improvement or a decrease in rSO2 value; Responders: patients which showed an improvement in $\mathrm{rSO} 2$ value to reach rSO2 of $>60 \%$ at $24 \mathrm{~h}$ and; Partially responders: patients in which the rSO2 value improved but did not reach $>60 \%$ at $24 \mathrm{~h}$; ICU LOS intensive care unit length of stay (days), $\mathrm{rSO}_{2}$ regional oxygen saturation index 
Table 3 Results of cox regression analysis

\begin{tabular}{|c|c|c|c|}
\hline Variable & Hazard ratio & $95 \% \mathrm{Cl}$ & $p$ value \\
\hline Presence of shock & 1.01 & $0.09-11.15$ & 0.98 \\
\hline Need of MV & 29.8 & $0.01-4.2 \mathrm{E}$ & 0.94 \\
\hline APACHE ॥ & 1.09 & $0.99-1.19$ & 0.052 \\
\hline "low" $\mathrm{rSO}_{2}$ (admission) & 8.99 & $1.05-76.8$ & 0.045 \\
\hline "low" rSO 2 (24 h) & 13.18 & $1.52-113.6$ & 0.019 \\
\hline
\end{tabular}

MV mechanical ventilation, APACHE II Acute Physiology and Chronic Health Evaluation, $\mathrm{rSO}_{2}$ regional oxygen saturation, $\mathrm{Cl}$ confidence interval

identification of variables capable of not only predicting outcomes but also providing a potential therapeutic target would be more useful in clinical applications.

Microvascular alterations are frequently observed in patients with sepsis. In humans, several studies have shown that severity of the alterations in microvascular perfusion is associated with poor outcome [12-14]. A crucial question is whether these microcirculatory alterations merely reflect the severity of the disease or contribute independently to mortality. Among the tools available for tissue microcirculation/oxygenation assessment, NIRS devices seem promising. It has been shown in different life-threatening conditions that muscle skeletal oxygen saturation might characterize tissue hypoperfusion and effectiveness of therapy in trauma [20] and septic shock $[17-19,21]$. However, the relationship between skeletal oxygen saturation with macrohemodynamics variables is not entirely clear. Small-sized trials showed that microvascular alterations were relatively independent of MAP, CO and vasopressor agent use $[19,31,32]$. In our study, no significant correlation was observed between the values of NIRS and classic hemodynamic variables. In contrast, other authors observed a significant relationship between $\mathrm{CO}$ and skeletal muscle oxygen saturation [20,33]. In this

Table 4 Area under ROC curve (AUROC). Discrimination for mortality of $\mathrm{rSO}_{2}$ and hemodynamic variables and APACHE ॥ score

\begin{tabular}{lcll}
\hline Variable & AUROC & $95 \% \mathrm{Cl}$ & $p$ value \\
\hline $\mathrm{rSO}_{2}$ baseline & 0.84 & $0.626-1.057$ & 0.004 \\
$24 \mathrm{~h}$ & 0.86 & $0.646-1.075$ & 0.002 \\
Lactate baseline & 0.57 & $0.334-0.820$ & 0.51 \\
$24 \mathrm{~h}$ & 0.69 & $0.434-0.951$ & 0.10 \\
$\mathrm{BD}$ baseline & 0.44 & $0.200-0.680$ & 0.61 \\
$24 \mathrm{~h}$ & 0.70 & $0.477-0.927$ & 0.08 \\
MAP baseline & 0.58 & $0.391-0.782$ & 0.46 \\
$24 \mathrm{~h}$ & 0.52 & $0.321-0.726$ & 0.83 \\
APACHE ॥ & 0.76 & $0.559-0.980$ & 0.02 \\
\hline
\end{tabular}

$\mathrm{Cl}$ confidence interval, $r \mathrm{SO}_{2}$ regional oxygen saturation index, $B D$ base deficit MAP medium arterial pressure, APACHE II Acute Physiology and Chronic Health Evaluation way, our data cannot be compared with that available in the literature using other NIRS devices. Important technical differences should be considered before interpreting and comparing data based on NIRS technology. In the near-infrared range, oxyhaemoglobin $\left(\mathrm{HbO}_{2}\right)$, deoxyhaeamoglobin $(\mathrm{Hb})$ and oxidized cytochrome oxidase (CytOx) have characteristic absorption spectra. In order to derive concentration changes simultaneously for $\mathrm{Hb}, \mathrm{HbO}_{2}$ and CytOx, values for absorption at four wavelengths of near infrared are often used. The calculation used to solve the modified Beer-Lambert equation at each of these wavelengths is known as an algorithm. Algorithms are different for each device and also vary depending on the presence of other chromophores and the precise values for the absorption coefficients chosen [34-36]. Recent work has applied different published algorithms to the same data set and revealed striking differences in the calculated concentration changes $[37,38]$. In addition, it is crucial to know the differential pathlength factor (DPF) when interpreting NIRS data. DPF is the distance travelled by each photon, and its value is derived from studies in healthy adults [39]; it may vary in other situations and is also wavelength-dependent. DPF may also change within the same subject over a period of time if the state of the tissue or tissue geometry alters [40]. Thus, probably, "normal" and critically "abnormal" tissue oxygenation values should be determined according to the critically ill patient population and the NIRS device used.

Besides differences regarding technical characteristics of each NIRS device, different values have been obtained when measuring $\mathrm{rSO}_{2}$ in different muscles. Our group found different values of $\mathrm{rSO}_{2}$ in brachioradialis and deltoid muscles of septic patients, although in each location "low" $\mathrm{rSO}_{2}$ values were associated with poor outcome [18]. Other groups have found these differences between muscles [41].

Although our patients in shock had lower values of $\mathrm{rSO}_{2}$ during the entire study period, we observed a nonsignificant relationship between MAP, vasopressor dose administered or $\mathrm{SvO}_{2}$ and $\mathrm{rSO}_{2}$. These findings may suggest that these variables do not affect $\mathrm{rSO}_{2}$ significantly. Classically, in septic shock, adequacy of perfusion for oxygen demand is assessed by serum lactate and base deficit levels $[11,15]$. In the present study, serum lactate and base deficit levels were not associated with poor outcome. Skeletal muscle $\mathrm{rSO}_{2}$ may provide a more accurate reflection of oxygen delivery because it represents the balance between the oxygen supply to the capillaries directly beneath the sensor and oxygen consumption at that site independently of global hemodynamic state [17]. The $\mathrm{rSO}_{2}$ is indicative of oxygen extraction from haemoglobin and in comparison with arterial oxygen saturation, and possibly $\mathrm{SvO}_{2}$, it might provide a more accurate picture of hypoxia [17]. In fact, according to present data, 
the microcirculatory response to the treatment administered might be evaluated by the variation of $\mathrm{rSO}_{2}$. Patients with basal "low" $\mathrm{rSO}_{2}$ that respond appropriately to early treatment (first $24 \mathrm{~h}$ ) and normalize the $\mathrm{rSO}_{2}(\geq 60 \%)$ presented an ICU evolution significantly better than patients who despite improving $\mathrm{rSO}_{2}$ did not reach this cut-off.

The discriminatory ability for mortality was substantially higher for $\mathrm{rSO}_{2}$ than serum lactate and base deficit (except for $24 \mathrm{~h}$ ). This suggests that skeletal muscle $\mathrm{rSO}_{2}$ can detect early poor tissue oxygenation that results in serum lactate or base deficit elevation during septic shock. Taking these into account, it is reasonable to think that $\mathrm{rSO}_{2}$ emerges as an early indicator of poor oxygenation with implications on prognosis. In addition, Cox regression analysis showed that "low" $\mathrm{rSO}_{2}$ value, both at ICU admission and at $24 \mathrm{~h}$, was independently associated with mortality.

Our study had several limitations. First, the sample size was small in a single centre, which may account for some lack of statistical significance. The small patient population also prevented a subgroup analysis to further examine the differences in the effects of $\mathrm{rSO}_{2}$ on clinical outcomes according to some special clinical condition. However, clear differences in $\mathrm{rSO}_{2}$ values were observed between survivors and non-survivors. This suggests that $\mathrm{rSO}_{2}$ gives early evidence of patients with severe CAP who suffer oxygenation alterations with prognostic implications. Second, we not have been able to calculate the sample size to be included because there is no previous data with this population of patients and this NIRS device. However, we calculate the statistical power of our study which has been very high. Accepting a risk alpha of 0.05 in a bilateral contrast with 26 subjects in the first group $(\geq 60 \%)$ and 14 in the second $(<60 \%)$, the power of the contrast of hypotheses is $94 \%$ to detect as a statistically significant difference that exists between 3, $5 \%$ in the first group and $50 \%$ in the second for mortality.

Third, NIRS does not directly measure microcirculatory flow. However, many studies $[42,43]$ have observed that NIRS values correlated well with global and specific organ perfusion parameters. In addition, NIRS signal is limited to vessels that have a diameter $<1 \mathrm{~mm}$ (arterioles, capillaries and venules) and may be a useful tool for non-invasive monitoring of microcirculation in septic patients [13]. Fourth, we evaluated ICU mortality and not longer-term mortality, but the latter may also be influenced by other factors that are more related to the underlying disease and comorbidities. Fifth, we only included patients with CAP for which our data cannot be translated to other populations of patients with sepsis. Finally, we did not carry out a vascular occlusion test (VOT). VOT might to improve and expand the predictive ability of $\mathrm{rSO}_{2}$ in several scenarios $[19,44,45]$.
However, our findings showed a high discriminatory power for absolute $\mathrm{rSO}_{2}$ values in accordance with our previous findings [17].

\section{Conclusions}

Our findings suggest that forearm skeletal muscle $\mathrm{rSO}_{2}$ determined at an early stage of severe community-acquired pneumonia is likely to be associated with outcome. Future studies are required to further substantiate our findings and to confirm the potential benefits of assessing skeletal muscle $\mathrm{rSO}_{2}$ on severe CAP.

\section{Competing interests \\ The authors declare that they have no competing interests. \\ This study was partially supported by grants from the Fondo de Investigación Sanitaria (FIS PI10/01538, PI13/02011) and SGR2013/0926 The funding agency had no role in the study design; in the collection, analysis or interpretation of data; in writing of the manuscript or in the decision to submit the paper for publication. The content is solely the responsibility of the authors and does not necessarily represent the official views of the Institute of Health Carlos III (ISC III) from Spain.}

\section{Authors' contributions}

AR had full access to all the data in the study and that he takes responsibility for the integrity of the data and the accuracy of the data analysis, including and especially any adverse effects. AR, LC, JM, MiM, MoM, MB, ST, SP, AGE and JCY have made substantial contributions to the conception and design, acquisition, analysis and interpretation of data. AR has drafted the submitted article. LC, JMC, MoM, SP and JG have revised the manuscript critically for important intellectual content. AR and JG have provided final approval of the version to be published. All authors read and approved final manuscript.

\section{Acknowledgements}

We thank J. Francisco Avilés MD, PhD, for his statistical assessment and Phil Hoddy for the revision of English.

\section{Author details}

'Joan XXIII University Hospital, Critical Care Department, IISPV/URV, Carrer Dr. Mallafre Guasch 4, 43007, Tarragona, Spain. ${ }^{2}$ Research Unit, Joan XXIII University Hospital, IISPV/URV, Tarragona, Spain. ${ }^{3}$ CIBER de enfermedades respiratorias (CIBERES), ISC III, Bunyola, Palma de Mallorca, Spain. ${ }^{4}$ Parc de Salut Mar, IMIM, Pneumology Department, CEXS, UPF, Barcelona, Spain.

${ }^{5}$ Critical Care Department, Mataró Hospital, Mataró, Spain.

Received: 28 August 2015 Accepted: 13 January 2016

Published online: 19 January 2016

\section{References}

1. Khawaja A, Sarwar Zubairi AB, Durrani FK, Zafar A. Etiology and outcome of severe community-acquired pneumonia in immunocompetent adults. BMC Infect Dis. 2013;13:94-9.

2. Ishiguro T, Takayanagi N, Yamaguchi S, Yamakawa H, Nakamoto K, Takaku Y, et al. Etiology and factor contributing to severity and mortality of community-acquired pneumonia. Intern Med. 2013;52:317-24.

3. Rodriguez A, Lisboa T, Blot S, Martin-Loeches I, Solé-Violan J, De Mendoza D, et al. Mortality in ICU patients with bacterial community-acquired pneumonia: when antibiotic are not enough. Intensive Care Med. 2009;35:430-8.

4. Bodí M, Rodríguez A, Solé-Violán J, Gilavert MC, Garnacho J, Blanquer J, et al. Antibiotic prescription for community-acquired pneumonia in the intensive care unit: impact of adherence to Infectious Diseases Society of America guidelines on survival. Clin Infect Dis. 2005;41:1709-16.

5. Rello J, Rodríguez A, Torres A, Roig J, Sole-Violan J, Garnacho-Montero J, et al. Implications of COPD in patients admitted to the intensive care unit by community-acquired pneumonia. Eur Respir J. 2006;27:1210-6.

6. Restrepo MI, Mortensen EM, Velez JA, Frei C, Anzueto A. A comparative study of community-acquired pneumonia patients admitted to the Ward and the ICU. Chest. 2008;133:610-7. 
7. Lisboa T, Blot S, Waterer GW, Canalis E, de Mendoza D, Rodriguez A, et al. Radiologic progression of pulmonary infiltrates predicts a worse prognosis in severe community-acquired pneumonia than bacteremia. Chest. 2009:135:165-72.

8. Rodríguez A, Mendia A, Sivvent JM, Barcenilla F, de la Torre-Prados MV, Solé-Violán J, et al. Combination antibiotic therapy improves survival in patients with community-acquired pneumonia and shock. Crit Care Med. 2007;35:1493-8.

9. Shorr AF, Bodi M, Rodríguez A, Solé-Violán J, Garnacho-Montero J, Rello J, et al. Impact of antibiotic guideline compliance on duration of mechanical ventilation in critically ill patients with community-acquired pneumonia. Chest. 2006;130:93-100.

10. Waterer GW, Kessler LA, Wunderink RG. Delayed administration of antibiotic and atypical presentation in community-acquired pneumonia. Chest. 2006;130:11-5.

11. Dellinger RP, Levy MM, Rhodes A, Annane D, Gerlach H, Opal SM, et al. Surviving sepsis campaign: international guidelines for management of severe sepsis and septic shock, 2012. Intensive Care Med. 2013;39:165-228.

12. Ellis CG, Jagger J, Sharpe M. The microcirculation as a functional system. Crit Care. 2005;9 suppl 4:53-8.

13. Ince $\mathrm{C}$. The microcirculation is the motor of sepsis. Crit Care. 2005;9 suppl 4:513-9.

14. De Backer D, Donadello K, Sakr Y, Ospina-Tascon G, Salgado D, Scolletta S, et al. Microcirculatory alterations in patients with severe sepsis: impact of time of assessment and relationship with outcome. Crit Care Med. 2013;41:791-9.

15. Suistomaa M, Uusaro A, Parviainen I, Ruokonen E. Resolution and outcome of acute circulatory failure does not correlate with hemodynamics. Crit Care. 2003;7:R52.

16. Gattinoni L, Brazzi L, Pelosi P, Latini R, Tognoni G, Pesenti A, et al. A trial of goal-oriented hemodynamic therapy in critically ill patients. SvO2 Collaborative Group. N Engl J Med. 1995;333:1025-32.

17. Rodríguez A, Lisboa T, Martín-Loeches I, Díaz E, Trefler S, Restrepo MI, et al. Mortality and regional oxygen saturation index in septic shock patients: a pilot study. J Trauma. 2011;70:1145-52.

18. Rodríguez A, Claverias L, Marín J, Magret M, Rosich S, Bodí M, et al. Regional oxygen saturation index ( $\mathrm{rSO} 2$ ) in brachioradialis and deltoid muscle. Correlation and prognosis in patients with respiratory sepsis. Med Intensiva. 2015;39:68-75

19. Creteur J, Carollo T, Soldati G, Buchele G, De Backer D, Vincent JL. The prognostic value of muscle $\mathrm{StO} 2$ in septic patients. Intensive Care Med. 2007:33:1549-56.

20. Ikossi DG, Knudson MM, Morabito DJ, Cohen MJ, Wan JJ, Khaw L, et al. Continuous muscle tissue oxigenation in critically injured patients. A prospective observational study. J Trauma. 2006;61:780-90.

21. Mesquida J, Espinal C, Gruartmoner G, Masip J, Sabatier C, Baigorri F, et al. Prognostic implications of tissue oxygen saturation in human septic shock Intensive Care Med. 2012;38:592-7.

22. Lim WS, Baudouin SV, George RC, Hill AT, Jamieson C, Le Jeune I, et al. BTS guidelines for the management of community-acquired pneumonia in adults. Thorax. 2009;64(3):iii 1-15.

23. Knaus WA, Draper EA, Wagner DP, Zimmerman JE. APACHE II: a severity of disease classification system. Crit Care Med. 1985:13:818-29.

24. Metnitz PG, Moreno RP, Almeida E, Jordan B, Bauer P, Campos RA, et al. SAPS 3-from evaluation of the patient to evaluation of the intensive care unit. Part 1: objectives, methods and cohort description. Intensive Care Med. 2005:31:1336-44.

25. Mandell LA, Wunderick RG, Anzueto A, Bartlett JG, Campbell GD, Dean NC, et al. Infectious Diseases Society of America/American Thoracic Society consensus guidelines on the management of the community-acquired pneumonia in adults. CID. 2007:44:27-72.

26. Blot SI, Rodríguez A, Solé-Violán J, Blanquer J, Almirall J, Rello J, et al. Effects of delayed oxygenation assessment on time to antibiotic delivery and mortality in patients with severe community-acquired pneumonia. Crit Care Med. 2007:35:2509-14.

27. Lim WS, van der Eerden MM, Laing R, Boersma WG, Karalus N, Town Gl, et al. Defining community acquired pneumonia severity on presentation to hospital: an international derivation and validation study. Thorax. 2003;58:377-82.

28. Leroy O, Mikolajczyk D, Devos P, Chiche A, Grunderbeeck NV, Boussekey N, et al. Validation of a prediction rule for prognosis of severe community-acquired pneumonia. Open Respir Med J. 2008:2:67-71.
29. Antunes G, Evans SA, Lordan JL, Frew AJ. Systemic cytokine levels in community-acquired pneumonia and their association with disease severity. Eur Respir J. 2002;20:990-5.

30. Bauer TT, Montón C, Torres A, Cabello H, Fillela X, Maldonado A, et al. Comparison of systemic cytokine levels in patients with acute respiratory distress syndrome, severe pneumonia, and controls. Thorax. 2000;55:46-52.

31. Baterman RM, Walley KR. Microvascular resuscitation as a therapeutic goal in severe sepsis. Crit Care. 2005;Suppl 4:S27-32.

32. van Beest PA, Vos JJ, Poterman M, Kalmar AF, Scheeren TWL. Tissue oxygenation as target for goal-directed therapy in high-risk surgery: a pilot study. BMC Anesthesiol. 2014;14:122.

33. Bezemer R, Karemaker JM, Klijn E, Martin D, Mitchell K, Grocott M, et al. Simultaneous multi-depth assessment of tissue oxygen saturation in thenar and forearm using near-infrared spectroscopy during a simple cardiovascular challenge. Crit Care. 2009:13 Suppl 5:55.

34. Hazeki O, Tamura M. Near-infrared quadruple wavelength spectrophotometry of the rat head. Adv Exp Med Biol. 1989;248:63-9.

35. Piantadosi CA. Absorption spectroscopy for assessment of mitochondrial function in vivo. Methods Toxicol. 1993;2:107-26.

36. Wickramasinghe $Y$, Thorniley M, Rolfe P, Houston R, Livera LN, Faris F. Developments of algorithms for non-invasive neonatal cerebral monitoring using NIRS. Proc 12th Ann Int Conf IEEE Eng. Biol Soc. 1990:49:762-6.

37. Owen-Reece H, Smith M, Elwell CE, Goldstone JC. Near infrared spectroscopy. Br J Anaesth. 1999:82:418-26.

38. Matcher SJ, Elwell CE, Cooper CE, Cope M, Delpy DT. Performance comparison of several published tissue near infrared spectroscopy algorithms. Anal Biochem. 1995;227:54-68.

39. Duncan A, Meek JH, Clemence M, Elwell CE, Tyszczuk L, Cope M, et al. Optical pathlength measurements on adult head, calf and forearm and the head of the newborn infant using phase resolved optical spectroscopy. Phys Med Biol. 1995;40:295-304.

40. Deply DT, Cope M, van der Zee P, Arridge SR, Wray S, Wyatt JS. Estimation of optical path length through tissue from direct time of flight measurement. Phys Med Biol. 1988;33:1433-42.

41. Gómez H, Mesquida J, Simon P, Kim HK, Puyana JC, Ince C et al. Characterization of tissue oxygen saturation and the vascular occlusion test: influence of measurements sites, probe sizes and deflation thresholds. Crit Care. 2009, (doi:10.1186/cc8001)

42. Nahum E, Skippen PW, Gagnon RE, Macnab AJ, Skarsgard ED. Correlation of nearinfrared spectroscopy with perfusion parameters at the hepatic and systemic levels in an endotoxemic shock model. Med Sci Monit. 2006;12:BR313-7.

43. Cohn SM, Varela JE, Giannotti G, Dolich MO, Brown M, Feinstein A, et al. Splanchnic perfusion evaluation during hemorrhage and resuscitation with gastric near-infrared spectroscopy. J Trauma. 2001;50:629-35.

44. Gómez H, Torres A, Polanco P, Kim HK, Zenker S, Puyana JC, et al. Use of non-invasive NIRS during a vascular occlusion test to assess dynamic tissue oxygen saturation response. Intensive Care Med. 2008;34:1600-7.

45. Payen D, Luengo C, Heyer L, Resche-Rigon M, Kerever S, Damoisel C, et al. Is thenar tissue hemoglobin oxygen saturation in septic shock related to macrohemodynamic variables and outcome? Crit Care. 2009;13 Suppl 5:56.

\section{Submit your next manuscript to BioMed Central and we will help you at every step:}

- We accept pre-submission inquiries

- Our selector tool helps you to find the most relevant journal

- We provide round the clock customer support

- Convenient online submission

- Thorough peer review

- Inclusion in PubMed and all major indexing services

- Maximum visibility for your research

Submit your manuscript at www.biomedcentral.com/submit 